Valuation Studies 8(1) 2021: 1-6

Editorial Note:

\title{
A Note on Transitions
}

\author{
Claes-Fredrik Helgesson
}

\section{New careers in New Towns}

It has become time for me to step down from my leading editorial role for Valuation Studies. We on the board of editors have for some time worked on a transformation and move of offices to Copenhagen Business School. Apart from the necessary reformulation discussed in a previous editorial note (Board of Editors 2020), this transition also relates to me when in 2019 I took on 'a new career in a new town'. The publication of this issue therefore marks an important further step in this process by concluding my leading editorial role for this journal.

I want to take this final opportunity to pen an editorial note to reflect briefly on the evolution of Valuation Studies. This exercise will touch on how both ideas and practices evolved. This means revisiting some of the thinking and doing over the past ten years.

\section{Beginnings: Starting and expanding conversations}

Most work I become engaged with begins with indeterminate and meandering conversations. It may take some shape in mind maps that outline questions, issues, and possible actions. Yet, the key in sustaining the realisation is gradually more focused conversations that outline plans and actions. The early conversations that developed into Valuation Studies were with Fabian Muniesa in early 2011, possibly even earlier. (There are records of earlier conversations involving

Claes-Fredrik Helgesson is Professor in Technology and Social Change and Director at the Centre for Integrated Research on Culture and Society (CIRCUS) at Uppsala

University. claes-fredrik.helgesson@circus.uu.se

(C) 2021 The author

(cc) BY-No This work is licensed under a Creative Commons Attribution-

NonCommercial 4.0 International License.

bttps://doi.org/10.3384/VS.2001-5992.2021.8.1.1-6

Hosted by Linköping University Electronic press

http://valuationstudies.liu.se 
others pointing in similar directions.) Soon, more entities became engaged in the still exploratory endeavour. This included staff at Linköping University Library, most notably David Lawrence and Peter Berkesand, who had routines on how to set up electronic open access journals. It further included a number of our colleagues who had expressed an interest in promoting the endeavour. I sent an application to support the creation of the journal to the Swedish Research Council in August 2011 indicating a proto-editorial advisory board including Patrik Aspers, Peter Karnøe, Hans Kjellberg, Andrea Mennicken, and Ebba Sjögren. The ambition of the endeavour was in the application phrased in terms that would sound broadly familiar to those who have followed the journal over the years:

This application concerns funding for establishing a new open access journal that will bring together several vibrant research fields ... The aim of the journal is to be a hub for work relating to the study of valuation as a social practice. More specifically, the journal will provide a space for the assessment and diffusion of research that is produced at the interface of a variety of approaches from several disciplines: new economic sociology, science and technology studies, organizational science, cultural anthropology, market studies, institutional perspectives in economics and economic history, accounting studies, cultural geography, philosophy ... The journal finds its primary niche not in a clear-cut disciplinary community but in the emerging network of sociologists, management scientists and economists, and others who meet and discuss valuation in multidisciplinary conferences (such as EGOS, SASE, and 4S), exchange ideas and read each other.

Notice that the grant application had been awarded funding for 2012 came in October or November 2011. The grant of $€ 10,000$ for 2012 stimulated much activity in actually realising the idea of the journal. What had been a possibility now had to take on a more realistic shape. Fabian and I took on roles as co-editors-in-chief. Members in the Values research programme in Linköping took on tasks in an emerging editorial office (Maria Eidenskog, Karin Thoresson, and Lotta Björklund Larsen). Advisory boards were expanded. The article layout was figured out and the public website was set up. Gradually, we became further acquainted with the personality of the locally developed manuscript management system. A call for papers was drafted.

The call for papers and the site were launched in June 2012. Now the venture was made public. The website received some 1,200 unique visitors in June alone, which was nice confirmation that there could be broader interest in this journal. Soon we received the first submissions, kicking off the editorial process of reading, soliciting reviews, making judgements on manuscripts and the incoming reviews, drafting and discussing editorial decision letters. The first issue was subsequently published in April 2013. The journal had come into existence. 
What was it that made us think that it could be meaningful to start a journal? We were thrilled when the home page saw many 'unique visitors', such as the more than 10,000 we had in 2013. Yet, the raison d'être of the journal was not tied to metrics. The scope and tone of the journal was invested in the core idea that meaningful scholarly work needed to be tied to a community of ongoing conversations. Important and exciting conversations are what makes scholarly work worthwhile and are necessary for fostering ideas. We live in an age of grand illusion that the meaningfulness of scholarly contributions can be valued with metrics such as citations, impact scores, and the like. We made a strong point neither to conflate the two, nor to think that the metrics was what ultimately mattered. What ultimately mattered to us was whether it could gather a community and start new conversations on valuations. As Fabian and I stated in our opening editorial:

The worth of the venture to start a new journal has to be assessed in how it engages to create new conversations and new ideas. (Helgesson and Muniesa 2013: 8)

I am satisfied to observe that the journal is part of a heterogenous community that contributes to it, reads it, and so on. There have been several workshops and conference sessions organised that more or less clearly related to the journal. A personally overwhelming moment was at 4S/EASST in Barcelona in 2016 where I co-organised a track of sessions together with Freyja Knapp, Kristin Asdal, Francis Lee, and Steve Woolgar. Titled 'Valuation practices at the margins', the open call attracted some 31 papers over seven sessions. Some of the contributions have appeared later as articles in the journal. I remember feeling that the venture felt anything but marginal.

Alongside the gradual emergence of a broader heterogenous community taking an interest in the journal, there also gradually emerged the tight-knit community known as the board of editors. This small group of fewer than ten scholars allowed us to distribute the caring for submissions across more pairs of hands. Yet, this group has never primarily been a mechanism for dividing up the workload. Not only are submissions discussed within the group, but the key feature of this collective lies in how we developed a style for working together, thinking and talking about the direction of the journal, where the conversations were going, and what care they and the journal needed. The ongoing conversations and the care this group displays have become the bedrock of Valuation Studies.

\section{Plenty of opportunities for learning}

There are more nuances to the many facets of academic publishing than I ever could have dreamed of when I began talking with Fabian about the possibility of starting a journal. Getting involved in the start- 
up of a journal provides many opportunities for learning. There are many things to appreciate when trying to care for-not managing-the delicate process where promising manuscripts from authors can become part of published issues. It involves attending to manuscripts, authors, reviewers, fellow editors, and readers. There is the intricacy of determining when manuscripts are ready to become finished articles and part of the broader conversation. There are the nooks and crannies of manuscript management systems. (Somewhat upping that particular ante, we changed our system twice.) One thing I have come to appreciate in all this is how apparently practical and managerial matters often are tied in to more fundamental issues.

I can readily admit that at times it has been difficult to make it all work as we would have wanted. I have, for instance, at times failed to make prompt decisions on manuscripts, unnecessarily delaying the editorial process. Having an editorial role in a scholarly journal clearly provides opportunities to reflect on any inclination to procrastinate that you might have. The board of editors has been a key group of scholarly friends when things have not worked out as planned.

Being involved in setting up and operating a new scholarly journal further provided me with more detailed insights into the many tensions in the landscape of contemporary academic publishing. One set of such pertinent tensions centres around different publishing models. At one end of the spectrum there is the non-profit open access model, like Valuation Studies, and at the other you find the large-scale for-profit publication model. Our choice to develop Valuation Studies as a smallscale university-based and community oriented open access venture gave us a particular outlook. I gradually learned, for instance, that there are many ways you can talk about costs related to scholarly publishing. Sometimes colleagues in academia questioned whether government funds really should be used to support open access journals. In doing so, they conveniently ignored the massive amounts of government funds used to pay for institutional subscriptions of commercially operated journals. Valuation Studies has always operated on a shoestring budget, even more so in later years when support from the Swedish Research Council was ended. It is a publication model that is tough to operate. Yet, there are also benefits and it is much easier to align it with important ideas of what scholarly communication is all about.

Academic publishing is immersed in a plethora of valuation practices. It is therefore not strange that it recurrently has figured in notes I have authored and co-authored for this journal (Helgesson 2016; Helgesson and Muniesa 2013, 2014; Helgesson and Woolgar 2018). I still contend that the many facets of academic publishing practices, and of scholarly endeavours more broadly, provide a rich site for examining valuations; how they are done and what they do. 


\section{Care for the conversations!}

Theodore Zeldin (2000) reminded us that conversation is more than exchanging facts:

When minds meet, they don't just exchange facts: they transform them, reshape them, draw different implications from them, engage in new trains of thought. Conversation doesn't just reshuffle the cards: it creates new cards. (Zeldin 2000: 50)

That it is why, I think, it is so important to care for the arenas where scholarly communities can meet and have meaningful conversations. It is further why it is key to keep that tricky balance of having a community open and evolving, while not losing sight of what keeps it together. It means keeping the conversation progressing rather than becoming repetitive and formulaic, which ties in to why the current reformulation of Valuation Studies is pertinent at this point. It is, as Zeldin put it '... up to us to decide on the kind of conversations we have' (Zeldin 2000: 50). I look forward to continuing to enjoy the conversations on pages of this journal and within this community.

Acknowledgment: Thanks to fellow editors José Ossandón, Trine Pallesen, and Fabian Muniesa for reading and commenting on an earlier version of this note. As I depart, I would furthermore like to thank other individuals and collectives that have been key in making Valuation Studies. First come the authors and reviewers. They are all key participants in the conversations that constitute the editorial process. It is easy to understand the importance for a new journal that there are authors who are willing to submit manuscripts to an uncertain new outlet. Thanks for your trust! The significance of dedicated reviewers is equally key, and their work often at best acknowledged by thanking 'two anonymous reviewers for their comments and suggestions'. Thanks! Then there is the invisible work of an editorial office where several individuals have filled key functions: Thanks to Lotta Björklund Larsen, Maria Eidenskog, Amelia Mutter, Johan Nilsson, Karin Thoresson, and Mella Köjs. Thanks to Rebecca Elfast for giving us the logo. Thanks to Pat Baxter for developing our style guide and consistent copy-editing. The dedicated staff at LiU e-press have also done immensely important, but largely invisible, work. Thanks David Lawrence, Peter Berkesand, and Edvin Erdtman. Thanks to the collectives on the advisory board. Your encouraging support has been key for reaching out. My final thanks go to my fellow members of the board of editors. Our collaboration over meetings and mails is at the heart of this and I am so happy that it is still ticking as I head off. And Fabian. Thanks for striking up this conversation and sticking with it. 


\section{References}

Board of Editors. 2020. "Towards a Reformulation." Valuation Studies 7(1): 1. https://doi.org/10.3384/VS.2001-5992.2020.7.1.1.

Helgesson, Claes-Fredrik. 2016. "Editorial Note: Folded Valuations?" Valuation Studies 4(2): 93-102.

Helgesson, Claes-Fredrik, and Fabian Muniesa. 2013. "For What It's Worth: An Introduction to Valuation Studies." Valuation Studies 1(1): 1-10.

Helgesson, Claes-Fredrik, and Fabian Muniesa. 2014. "Editorial Note: Valuation Is Work." Valuation Studies 2(1): 1-4.

Helgesson, Claes-Fredrik, and Steve Woolgar. 2018. "Valuation Mishaps and the Choreography of Repair." Valuation Studies 5(2): 145-162.

Zeldin, Theodore. 2000. Conversation. Mahwah, NJ: HiddenSpring.

Claes-Fredrik Helgesson is Professor in Technology and Social Change and since 2019 has been Director at the Centre for Integrated Research on Culture and Society (CIRCUS) at Uppsala University. The core mission of CIRCUS is to facilitate new cross-cutting research endeavours within Uppsala University with a focus on collaborations centred in the humanities and social sciences. Helgesson was a cofounding editor of this journal, which published its first issue in 2013. This is his final editorial note in that capacity. Helgesson is co-editor with David Moats, Else Vogel, and Steve Woolgar of The Imposter as Social Theory: Thinking with Gatecrashers, Cheats and Charlatans (Bristol University Press, 2021). 